\title{
Retained gastric band port and tube 5 years after gastric band removal and laparoscopic Roux-en-Y gastric bypass: a case report
}

\author{
Ahmad Ghazal', Mourad Niazi ${ }^{2}$, Israa Kannas ${ }^{3}$, Asmaa Alhasan ${ }^{3}$ and Hanadi Hawa ${ }^{3 *}$
}

\begin{abstract}
Background: While LAGB has become uncommon in the bariatric surgery practice, band removal with or without revision surgery is still common. Retained postoperative foreign body, of which surgical sponges are the most common, is a rare condition. We report a rare case of retained gastric band port and the attached tube.

Case presentation: A 31-year-old Caucasian female presented to the outpatient clinic, 5 years after her last surgery, complaining of a left upper quadrant abdominal mass over the last 2 years. She had a history of 2 weight loss operations. She had no significant family history nor smoking. CT of the abdomen and pelvis revealed a retained foreign body. On exploration, the port with $10 \mathrm{~cm}$ of the connected tube was found and removed through a small incision without laparotomy. The patient made an uneventful recovery.

Conclusion: A bariatric surgeon should be involved in the evaluation of any patient who complains of abdominal pain and/or palpable mass if she/he has a previous weight loss procedure because the bariatric surgeon is fully aware of the possible complications of the bariatric surgeries.
\end{abstract}

Keywords: Retained gastric band tube, Forgotten foreign body, Gastric band removal, Retained port, Case report

\section{Background}

While LAGB has become uncommon in the bariatric surgery practice, band removal with or without revision surgery is still common. Surgeons performing band removal should be aware of the possible pitfalls and complications of this procedure [1].

Pouch enlargement, band slippage, band erosion, port-site infections and port breakage represent the complications most commonly associated with LAGB [2]. Procedures performed to remove gastric band devices can themselves be subject to complications including retained surgical items [3]. Retained postoperative foreign body, of which surgical sponges are the most common, is a rare condition [4]. We report a rare case of forgotten gastric band port with the attached tube 5

\footnotetext{
* Correspondence: hanadiahmadhawa1993@gmail.com

${ }^{3}$ Faculty of Medicine, University of Aleppo, Aleppo, Syria

Full list of author information is available at the end of the article
}

years after gastric band removal and laparoscopic Roux-en-Y gastric bypass.

\section{Case presentation}

A 31-year-old Caucasian female presented to the outpatient clinic five years after her last surgery complaining of a left upper quadrant abdominal mass which is painful on movement, the mass size increased gradually over the last 2 years. She had no fever, diarrhea/constipation or nausea/vomiting.

She had a history of LAGB 10 years ago. Five years later she had a revision surgery due to weight loss failure, the gastric band was removed and laparoscopic Roux-en-Y gastric Bypass was done in the same procedure. Her past medical history included hypothyroidism 13 years ago medically treated by a daily dose of L-thyroxine. She had no significant family history nor smoking.

(c) The Author(s). 2018 Open Access This article is distributed under the terms of the Creative Commons Attribution 4.0 International License (http://creativecommons.org/licenses/by/4.0/), which permits unrestricted use, distribution, and reproduction in any medium, provided you give appropriate credit to the original author(s) and the source, provide a link to the Creative Commons license, and indicate if changes were made. The Creative Commons Public Domain Dedication waiver (http://creativecommons.org/publicdomain/zero/1.0/) applies to the data made available in this article, unless otherwise stated. 
On examination, the patient was afebrile. The abdomen was soft and non distended, the surgical scars were healed. A $4 \times 4 \mathrm{~cm}$, symmetric mass with normal overlying skin was found in the left upper quadrant. This mass was spherical, superficial, tender, firm, mobile and didn't disappear by compression. There was no bruit or lymphadenopathy.

Laboratory findings including complete blood count, liver function tests, and renal function tests were within normal. The differential diagnosis was port site hernia or retained foreign body.

Further investigations included $\mathrm{CT}$ of the abdomen and pelvis with oral contrast revealed subcutaneous spherical foreign body (probably the port) with the connected tube extending $10 \mathrm{~cm}$ into the abdominal cavity (Fig. 1). On exploration, the port with $10 \mathrm{~cm}$ of the connected tube was found and removed through a small incision without laparotomy. The patient had an uneventful recovery and was discharged on the same postoperative day. The patient expressed her happiness because minimally invasive surgery was done.

\section{Discussion and conclusion}

Gastric band removal is a common procedure [3]. However, forgetting some components is rarely reported in the literature [3].

Cattanach et Teague [3] reported three cases of retained gastric band components after the removal procedures.

Starnes et al. reported a case of retained gastric band tube [1]. Felder et al. reported a case of gastric band as a retained foreign body [5].

Gastric band removal and laparoscopic Roux-en-Y gastric bypass can be a prolonged procedure when there are adhesions. Moreover, the surgical team becomes exhausted at the end of the procedure which may lead to such mistakes. That was the case in our patient where the procedure time was $210 \mathrm{~min}$, the retained foreign body was the port with the connected tube discovered 5 years after gastric band removal and laparoscopic Roux-en-Y gastric bypass.

The main complaint of the patient was a left upper quadrant abdominal mass increased in size over the last 2 years. CT of the abdomen and pelvis could detect a retained foreign body and that was the only necessary diagnostic investigation.

On review, the removal of the gastric band port wasn't mentioned in the patient's medical record so we would suggest a checklist to be a part of the surgical notes of gastric band removal procedures.

The possibility of a retained foreign body should be in the differential diagnosis of any postoperative patient who presents with pain, infection, or palpable mass [6].

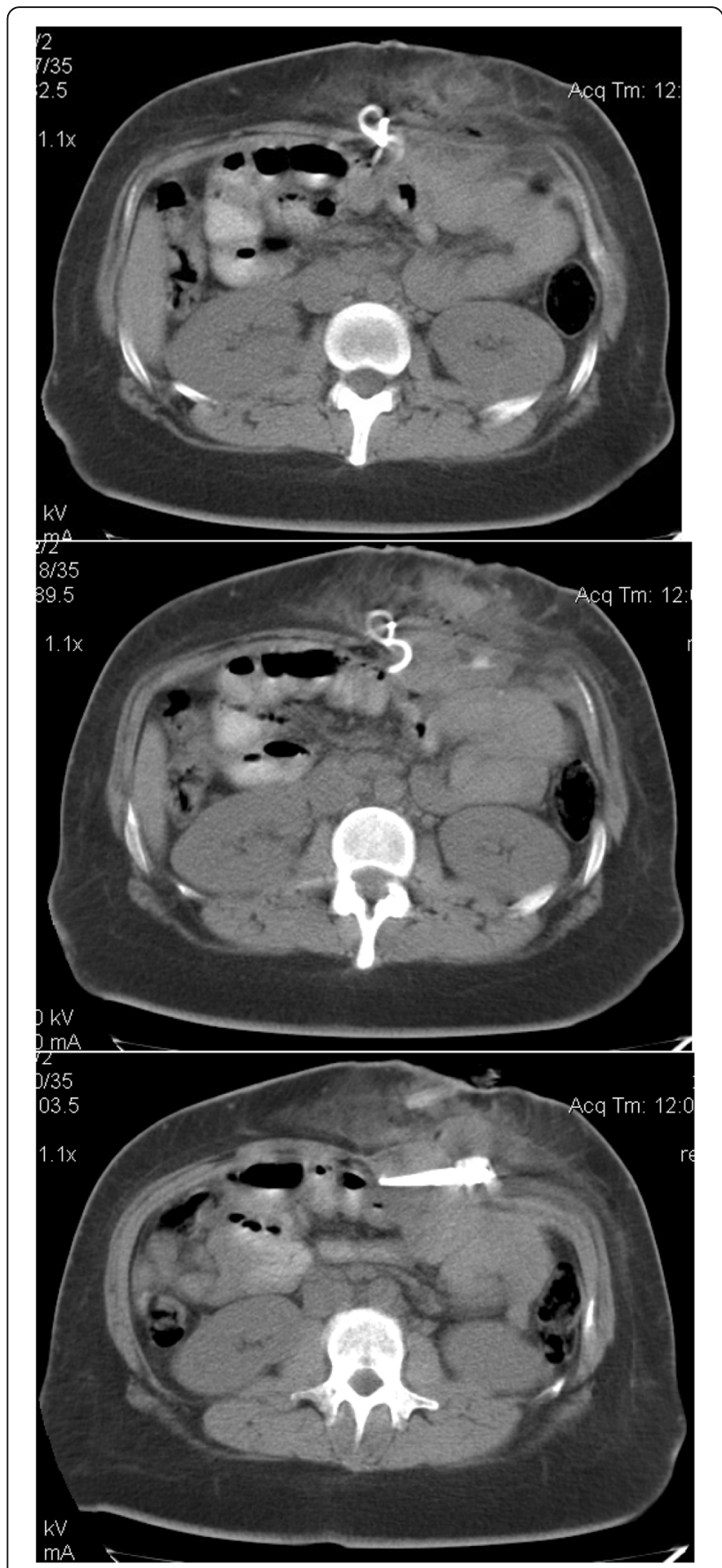

Fig. 1 CT of the abdomen and pelvis with oral contrast revealed subcutaneous spherical foreign body (probably the port) with the connected tube extending $10 \mathrm{~cm}$ into the abdominal cavity

From a medico-legal standpoint, the surgical team should be fully aware of the consequences of the retained foreign bodies. Therefore, a double check should be done to avoid such cases. Fortunately, the patient didn't claim against the responsible surgeon for retained gastric band port but that doesn't apply to every patient. 
Detailed history and full clinical examination in addition to a high index of suspicion are mandatory to evaluate patients who have retained foreign body. Hospitals also should develop strategies for LAGB removal procedures to avoid medico-legal issues. Finally, a bariatric surgeon should be involved in the evaluation of any patient who complains of abdominal pain and/or palpable mass if she/he has a previous weight loss procedure because the bariatric surgeon is fully aware of the possible complications of the bariatric surgeries.

\section{Abbreviations}

CT: Computerized tomography; LAGB: Laparoscopic adjustable gastric band

\section{Availability of data materials}

The data are completely available in this article.

Ethical approval and consent to participate

Not applicable.

\section{Funding}

There is none.

\section{Authors' contributions}

AG and MN performed the current surgery, supervised the study, drafted the article, analyzed and interpreted the data, critically revised the article. IK, AA, $\mathrm{HH}$ made a substantial contribution to conception and design, acquisition of data, analysis, and interpretation of data, drafting, and revision of the article.

All authors read and approved the final version of the manuscript.

\section{Consent for publication}

Written informed consent was obtained from the patient for publication of this case report and any accompanying images.

\section{Competing interests}

The authors declare that they have no competing interest.

\section{Publisher's Note}

Springer Nature remains neutral with regard to jurisdictional claims in published maps and institutional affiliations.

\section{Author details}

${ }^{1}$ Surgery Department, Aleppo University Hospital, Aleppo, Syria. ${ }^{2}$ Bariatric and laparoscopic surgery, Ohio Clinic, Dubai, UAE. ${ }^{3}$ Faculty of Medicine, University of Aleppo, Aleppo, Syria.

Received: 14 June 2018 Accepted: 15 November 2018

Published online: 22 November 2018

\section{References}

1. Starnes C, Mehta SS, Walker PA, Bajwa KS, Wilson EB, Shah SK. Words of caution regarding adjustable gastric band tubing. CRSLS. 2015. https://doi. org/10.4293/CRSLS.2015.00017.

2 Eid I, Birch DW, Sharma AM, Sherman V, Karmali S. Complications associated with adjustable gastric banding for morbid obesity: a surgeon's guide. Can $J$ Surg. 2011;54(1):61-6 https://doi.org/10.1503/cjs.015709.

3. Cattanach $D$, Teague B. Retained foreign body after adjustable gastric band removal: a case series. Obes Surg. 2017;27(12):3337-40 https://doi.org/10. 1007/s11695-017-2937-6

4. Sun HS, Chen SL, Kuo CC, Wang SC, Kao YL. Gossypiboma--retained surgical sponge. J. Chin. Med. Assoc. 2007;70(11):511-3 https://doi.org/10.1016/ S1726-4901(08)70051-0.

5. Felder S, Liou D, Gangi A. Gastric adjustable band as a retained foreign object: a case report. Bariatric Surg Pract Patient Care. 2013;8(4):166-8 https://doi.org/10.1089/bari.2013.0004

6. Gibbs VC, Coakley FD, Reines HD. Preventable errors in the operating room: retained foreign bodies after surgery. Curr Probl Surg. 2007;44(5):281-3377 https://doi.org/10.1067/j.cpsurg.2007.03.002.
Ready to submit your research? Choose BMC and benefit from:

- fast, convenient online submission

- thorough peer review by experienced researchers in your field

- rapid publication on acceptance

- support for research data, including large and complex data types

- gold Open Access which fosters wider collaboration and increased citations

- maximum visibility for your research: over $100 \mathrm{M}$ website views per year

At BMC, research is always in progress.

Learn more biomedcentral.com/submissions 